\title{
Is there alteration in aortic stiffness in Leber hereditary optic neuropathy?
}

\author{
A. NEMES ${ }^{1,2}$, I.F.M. DE COO ${ }^{3}$, L. SPRUIJT' ${ }^{4}$, H.J.M. SMEETS ${ }^{5}$, P.F. CHINNERY, O.I.I. SOLIMAN ${ }^{1,7}$, \\ M.L. GELEIJNSE ${ }^{1}$, F.J. TEN CATE 1 \\ ${ }^{1}$ Department of Cardiology, Thoraxcentre, Erasmus Medical Center, Rotterdam - The Netherlands \\ ${ }^{2} 2$ nd Department of Medicine and Cardiology Center, University of Szeged, Szeged - Hungary \\ ${ }^{3}$ Department of Neurology, Erasmus Medical Center, Rotterdam \\ ${ }^{4}$ Department of Human Genetics, Radboud University Nijmegen Medical Center, Nijmegen \\ ${ }^{5}$ Research Institute Growth and Development (GROW), University of Maastricht, Maastricht - The Netherlands \\ ${ }^{6}$ Mitochondrial Research Group, The Medical School, University of Newcastle upon Tyne, Newcastle upon \\ Tyne - England \\ ${ }^{7}$ Department of Cardiology, Al-Hussein University Hospital, Al-Azhar University, Cairo - Egypt
}

\begin{abstract}
PURPOSE. Leber hereditary optic neuropathy (LHON) is recognized as the most common cause of isolated blindness in young men. The current study was designed to test whether LHON as a mitochondrial disease is associated with vascular functional alterations characterized by aortic elastic properties during echocardiography.

Methods. A total of 19 patients with typical features of LHON aged $42 \pm 13$ years (10 males) were included. Their results were compared to 19 age- and gender-matched healthy controls. Aortic stiffness index was calculated from the echocardiographically derived aortic diameters and the clinical blood pressure data.

RESULTS. In this patient population, the point mutation was present in $3460 G>A$ position in five cases, in 11778G $>A$ position in five cases, and in 14484T $>C$ position in nine patients. Diastolic aortic diameter $(26.0 \pm 2.5 \mathrm{~mm}$ vs $28.4 \pm 4.1 \mathrm{~mm}, \mathrm{p}<0.05)$ and aortic stiffness index $(5.1 \pm 2.6$ vs $12.0 \pm 7.9$, $p<0.05)$ were significantly increased in $L H O N$ patients compared to controls.

ConcLUSIONS. Aortic stiffness can be increased in LHON disease, but further studies are warranted to confirm these findings in a larger LHON patient population with a more reliable method focusing on the pathophysiologic background. (Eur J Ophthalmol 2008; 18: 309-12)
\end{abstract}

KEY Words. Aortic stiffness, Echocardiography, Leber hereditary optic neuropathy

Accepted: October 22, 2007

\section{INTRODUCTION}

Leber hereditary optic neuropathy (LHON) is recognized as the most common cause of isolated blindness in young men with an estimated incidence of 1 in 50,000. Typically LHON presents as subacute painless visual loss with funduscopic changes of a peripapillary telangiectatic microangiopathy in the early stages (1), later followed by nonspecific optic atrophy. The demonstration that classical LHON is only inherited through females and the identification of exclusive maternal transmission of mitochondrial DNA (mtDNA) raised the hypoth- esis that a mtDNA defect might be responsible (2). The marked incomplete penetrance and gender bias indicate that additional genetic (nuclear or mitochondrial) and epigenetic factors may modulate the phenotype expression of LHON disease. However, the pathogenesis of LHON remains unclear. In several studies it has been demonstrated that mitochondrial damage or dysfunction is associated with cardiovascular disease $(3,4)$. The current study was designed to test whether LHON as a mitochondrial disease is associated with vascular functional alterations characterized by aortic elastic properties during echocardiography. 


\section{MATERIALS AND METHODS}

As a part of a prospective study to evaluate possible cardiovascular alterations in LHON disease, elastic properties of the aorta have been evaluated in a series of LHON patients. The present study comprised 19 patients with typical features of LHON aged $42 \pm 13$ years (10 males) (Tab. I). Their results were compared to 19 age- and gender-matched healthy controls. None of the patients or control subjects received therapeutic drugs. Informed consent was obtained from each patient and the study was approved by the institutional review board. In all patients blood pressure was measured in the supine position with a mercury sphygmomanometer. None of the patients or control subjects used coffee or tea within 1 hour before blood pressure measurements and by exclusion none of the patients or control subjects was a smoker. All subjects underwent a complete two-dimensional transthoracic echocardiography and Doppler study using a Philips Sonos 7500 system (Philips, Best, The Netherlands) in the left lateral decubitus position from multiple windows. Systolic and diastolic ascending aortic diameters (SD and DD, respectively) were recorded in M-mode at a level of $3 \mathrm{~cm}$ above the aortic valve from a parasternal long-axis view according to the method described previously (Fig. 1) (5). SD and DD were measured the time of maximum aortic anterior motion and at the peak of the QRS complex, respectively. Aortic stiffness index ( $\beta$ ) was calculated from the echocardiographically derived aortic diameters and the clinical blood pressure by using the following formula [In(SBP/DBP)]/[(SD-DD)/DD], where In is the natural logarithm. All data are reported as mean \pm standard deviation. For comparing variables, the Student $t$ test was used (SPSS 12.0 software, SPSS Inc., Chicago, IL, USA). A value of $p<0.05$ was considered statistically significant. Interobserver reproducibility for measuring systolic and diastolic aortic diameters in our institution is 91 and $91 \%$, respectively (5).

\section{RESULTS}

Clinical and demographic data of LHON patients and controls are presented in Table I. In this patient population, the point mutation was present in $3460 \mathrm{G}>\mathrm{A}$ position in five cases, in $11778 \mathrm{G}>\mathrm{A}$ position in five cases, and in $14484 \mathrm{~T}>\mathrm{C}$ position in nine patients. Individual values of aortic stiffness indices of LHON patients and controls are presented in Figure 2. Mean diastolic aortic diameter and mean aortic stiffness index were significantly increased in LHON patients compared to controls (even after the exclusion of 2 outliers).

\section{DISCUSSION}

To our knowledge, this is the first report to evaluate vascular elastic properties of the large arteries in patients with LHON disease. The main finding of the present study is that in a LHON patient population, the mean aortic stiffness

TABLE I - ECHOCARDIOGRAPHIC AND BLOOD PRESSURE DATA IN PATIENTS WITH LHON AND NORMAL SUBJECTS

\begin{tabular}{lcc}
\hline & Group 1 (normal subjects) & Group 2 (LHON disease cases) \\
\hline LV end-diastolic diameter (mm) & $49.5 \pm 6.7$ & $50.5 \pm 4.7$ \\
LV end-systolic diameter (mm) & $31.1 \pm 8.5$ & $32.7 \pm 4.0$ \\
LV ejection fraction (\%) & $68.9 \pm 7.7$ & $58.8 \pm 6.5$ \\
Systolic aortic diameter (mm) & $28.6 \pm 2.0$ & $30.1 \pm 4.3$ \\
Diastolic aortic diameter (mm) & $26.0 \pm 2.5$ & $28.4 \pm 4.1^{\star}$ \\
Pulsatile change in aortic diameter (mm) & $2.6 \pm 1.3$ & $1.7 \pm 1.0^{\star}$ \\
Systolic blood pressure (mm Hg) & $134.4 \pm 14.2$ & $131.7 \pm 21.7$ \\
Diastolic blood pressure (mm Hg) & $87.3 \pm 8.0$ & $78.8 \pm 11.6^{\star}$ \\
Aortic pulse pressure $(\mathrm{mm} \mathrm{Hg})$ & $47.2 \pm 14.5$ & $52.9 \pm 16.2$ \\
Aortic stiffness index $(\beta)$ & $5.1 \pm 2.6$ & $12.0 \pm 7.9 \dagger$ \\
\hline
\end{tabular}

Continuous variables are given as mean \pm standard deviation

${ }^{*} \mathrm{p}<0.05$.

$\mathrm{tp}<0.001$.

$\mathrm{LV}=$ Left ventricular; LHON = Leber hereditary optic neuropathy 


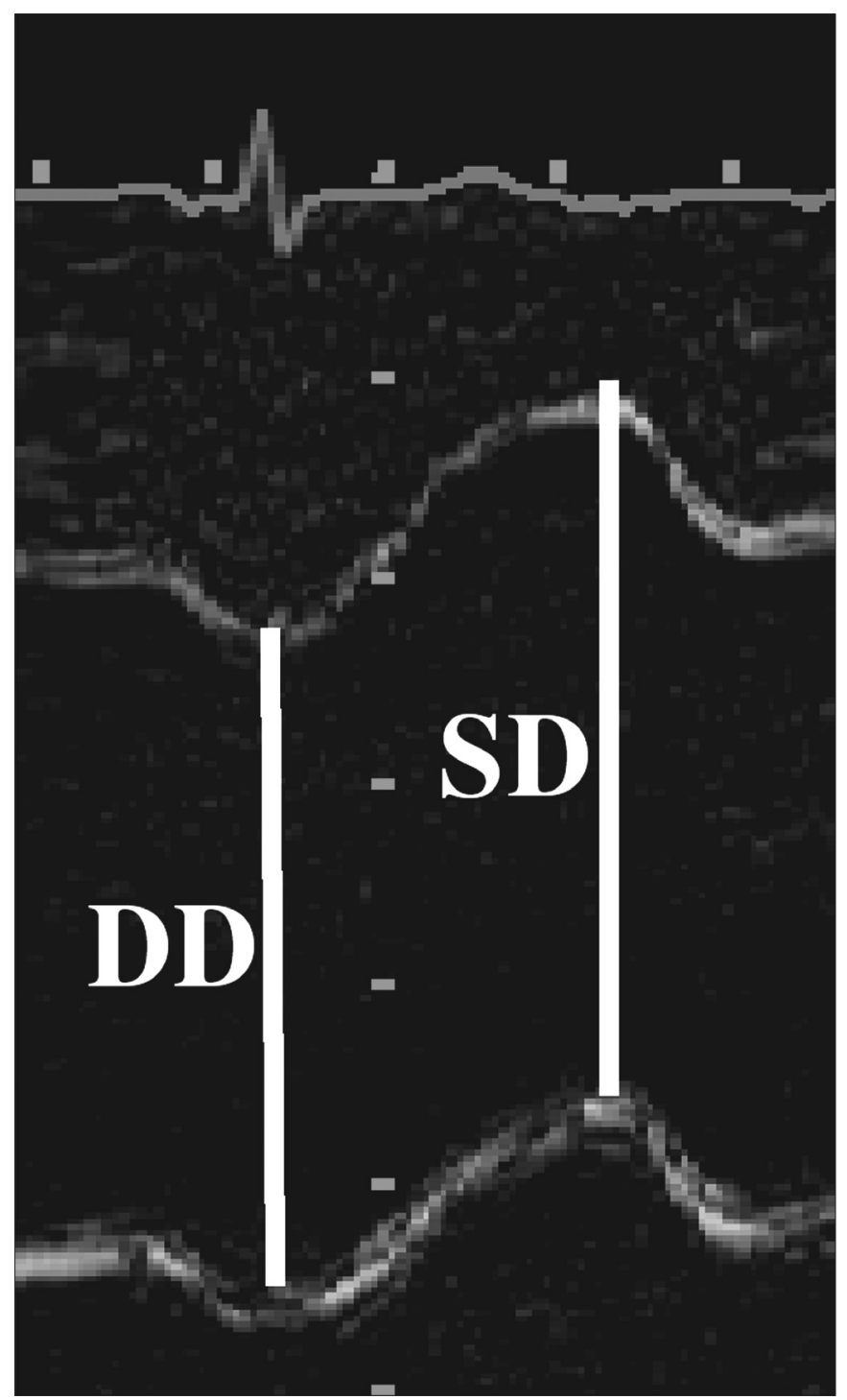

Fig. 1 - Measurements of systolic (SD) and diastolic (DD) diameters of the ascending aorta are shown on the M-mode tracing obtained at a level $3 \mathrm{~cm}$ above the aortic valve.

index is increased compared to matched controls. However, there were no genetic, clinical, or echocardiographic characteristics correlating with aortic stiffness index.

Increased arterial stiffness is an independent risk factor and predictor of cardiovascular mortality in a variety of diseases. There are numerous techniques for assessing the early stages of vascular disease and stiffness including pulse wave analysis or direct measurements. Direct measurement of arterial stiffness requires invasive techniques unsuitable for routine clinical practice. Recent studies demonstrated that pulsatile changes in ascending

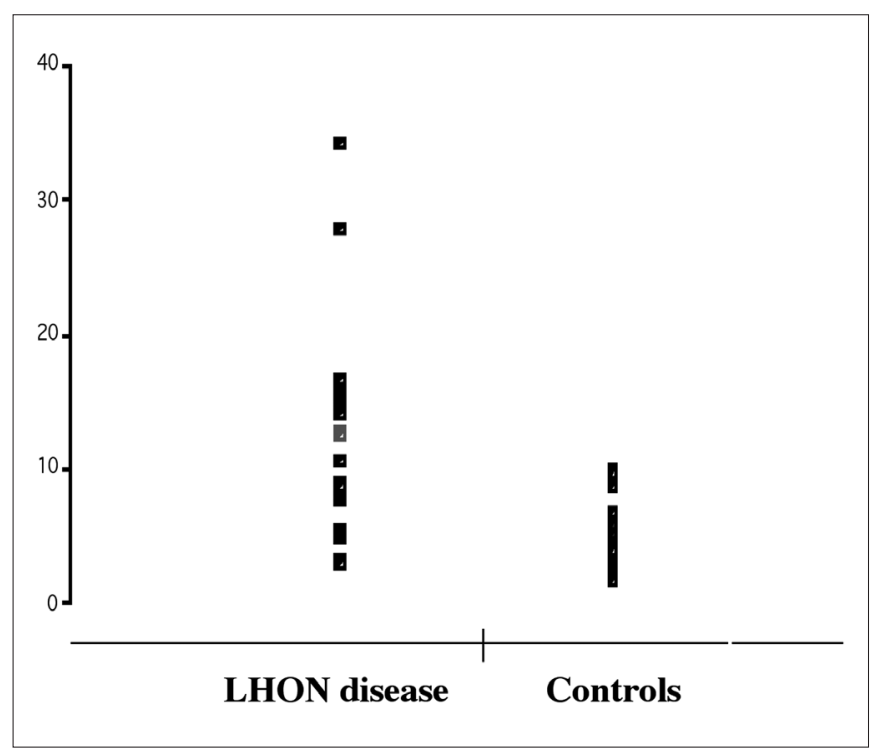

Fig. 2 - Individual $\beta$ indices of Leber hereditary optic neuropathy patients and control subjects.

aortic vessel diameter can be indirectly registered during routine transthoracic echocardiography. Stefanadis et al described that noninvasive measurements of aortic distensibility by echocardiography, based on aortic dimensions and blood pressure data, are as accurate as invasive methods (6).

The pathophysiologic mechanism of LHON is unclear. Although most of the early studies focused on bioenergetic defect, others suggested that additional genetic (mitochondrial or nuclear) and/or epigenetic factors (smoking, alcohol consumption) are also involved. Although none of the LHON patients had cardiac problems in the present study, the average of aortic stiffness indices was increased. There was no genetic, clinical, or echocardiographic parameter which correlated with increased aortic elastic properties. However, there are several theories to explain our findings. First, Wallace et al confirmed mtDNA involvement in LHON by identifying point mutations in mtDNA (7). Several neurologic abnormalities have been described in patients with LHON and pathologic mitochondrial point mutations $3460 \mathrm{G}>\mathrm{A}, 11778 \mathrm{G}>\mathrm{A}$, or $14484 \mathrm{~T}>\mathrm{C}$. In recent studies, a relationship between mitochondrial dysfunction and cardiovascular disease has also been demonstrated $(3,4)$. The microangiopathic appearance of the optic disc vessels in the acute stages and the presence of cerebrospinal fluid protein have raised the possibility of autoimmune mechanisms in the pathogene- 
sis of LHON (8). An autoimmune etiology of LHON might explain our findings since it is well known that other autoimmune disorders are related to increased vascular stiffness $(9,10)$. Rheumatology serology or inflammatory assessment were not performed in our patients. Finally, epigenetic factors (smoking, alcohol consumption) are known to be related to aortic stiffening.

It can be concluded that aortic stiffness is increased in LHON disease, but further studies are warranted to confirm our findings in a larger LHON patient population with a more reliable method focusing on the pathophysiologic background.

\section{ACKNOWLEDGEMENTS}

This study was supported in part by the EU-FP6 STREP MITOCIRCLE.

The authors report no conflicts of interest.
Reprint requests to:

Attila Nemes, MD

Department of Cardiology

Thoraxcenter

Erasmus Medical Center Rotterdam

Dr Molewaterplein 40

3015 GD, Room Ba304

Rotterdam, The Netherlands

nemes@in2nd.szote.u-szeged.hu

\section{REFERENCES}

1. Nikoskelainen E, Hoyt WF, Nummelin K. Ophthalmoscopic findings in Leber's hereditary optic neuropathy. II. The fundus findings in the affected family members. Arch Ophthalmol 1983; 101: 1059-68.

2. Erickson RP. Leber's optic atrophy, a possible example of maternal inheritance. Am J Hum Genet 1972; 24: 348-9.

3. Corral-Debrinski M, Shoffner JM, Lott MT, Wallace DC. Association of mitochondrial DNA damage with aging and coronary atherosclerotic heart disease. Mutat Res 1992; 275: 169-80.

4. Corral-Debrinski M, Stepien G, Shoffner JM, Lott MT, Kanter $\mathrm{K}$, Wallace DC. Hypoxemia is associated with mitochondrial DNA damage and gene induction. Implications for cardiac disease. JAMA 1991; 266: 1812-6.

5. Nemes A, Galema TW, Geleijnse ML, et al. Aortic valve replacement for aortic stenosis is associated with improved aortic distensibility at long-term follow-up. Am Heart $\mathrm{J}$ 2007; 153: 147-51.
6. Stefanadis C, Stratos C, Boudoulas H, Kourouklis C Toutouzas P. Distensibility of the ascending aorta: comparison of invasive and non-invasive techniques in healthy men and in men with coronary artery disease. Eur Heart J 1990; 11: 990-6.

7. Wallace DC, Singh G, Lott MT, et al. Mitochondrial DNA mutation associated with Leber's hereditary optic neuropathy. Science 1988; 242: 1427-30.

8. Schapira AH, Cock HR. Mitochondrial myopathies and encephalomyopathies. Eur J Clin Invest 1999; 29: 886-98.

9. Bjarnegrad N, Bengtsson C, Brodszki J, Sturfelt G, Nived $\mathrm{O}$, Lanne T. Increased aortic pulse wave velocity in middle aged women with systemic lupus erythematosus. Lupus 2006; 15: 644-50.

10. Turesson C, Jacobsson L, Ryden Ahlgren A, Sturfelt G, Wollmer P, Lanne T. Increased stiffness of the abdominal aorta in women with rheumatoid arthritis. Rheumatology (Oxford) 2005; 44: 896-901. 